\title{
La guerra de los Ochenta Años en el teatro y en la narrativa: Maastricht y Breda
}

\section{The Eighty Years War in Theater and Narrative: Maastricht and Breda}

\author{
Pilar de la Rosa Delgado \\ UNED \\ ESPAÑA \\ pdelarosa5@flog.uned.es \\ [Hipogrifo, (issn: 2328-1308), 9.1, 2021, pp. 519-541] \\ Recibido: 09-09-2020 / Aceptado: 12-11-2020 \\ DOI: http://dx.doi.org/10.13035/H.2021.09.01.30
}

Resumen. En el contexto de la guerra entre la corona española y las Provincias Unidas, la conquista de las ciudades de Maastricht y Breda fue muy significativa desde un punto de vista político para España.

El soldado Alonso Vázquez y el jesuita Herman Hugo vivieron y narraron los sucesos acaecidos durante el cerco de las dos ciudades en las obras Sucesos de Flandes y Francia del tiempo de Alejandro Farnesio, y en Obsidio Bredana, respectivamente. Sobre el sitio de estas dos ciudades y basándose en las obras mencionadas, los dos principales dramaturgos del Barroco español, Lope y Calderón, escribieron los dramas El asalto de Mastrique por el príncipe de Parma y El sitio de Bredá.

Palabras clave. Guerra de los Ochenta Años; Maastricht; Breda; Alonso Vázquez; Herman Hugo; Lope de Vega; Calderón de la Barca.

Abstract. In the context of the war between the Spanish crown and the United Provinces, the conquest of the cities of Maastricht and Breda was very significant from a political point of view for Spain. The soldier Alonso Vázquez and the Jesuit Herman Hugo lived and narrated the events that occurred during the siege of the two cities in the plays Sucesos de Flandes y Francia del tiempo de Alejandro Farnesio, and in Obsidio Bredana, respectively. On the site of these two cities, and based 
on the aforementioned plays, the two main Spanish Baroque playwrights, Lope and Calderón, wrote the dramas El asalto de Mastrique por el príncipe de Parma and El sitio de Bredá.

Keywords. Eighty Years War; Maastricht; Breda; Alonso Vázquez; Herman Hugo; Lope de Vega; Calderón de la Barca.

\section{INTRODUCCIÓN}

Durante los sucesivos reinados de la casa de Austria, muy especialmente durante los reinados de Carlos I, Felipe II y Felipe IV, fueron muy pocos los años en que la corona no estuvo en guerra y se podría decir que en paz ninguno, no es de extrañar, por tanto, que durante el Siglo de Oro se viviera una singular cultura de la guerra, como señaló García Hernán (2006).

Esta situación de conflicto permanente, aunque fuera a miles de kilómetros de España, dio lugar a que numerosas obras de teatro, el género por antonomasia del Siglo de Oro, tuvieran como protagonistas batallas, generales y soldados. Igualmente, militares u otros implicados en las contiendas, como el jesuita Hugo, escribirán sus crónicas o memorias, más o menos verídicas o incluso noveladas, sobre sus experiencias.

Dentro de las guerras en las que la monarquía española participó durante los siglos XVI y XVII destaca la que mantuvo en Flandes conocida como la Guerra de los Ochenta años. Enmarcados en este largo conflicto, se encuentran los sitios y conquistas de dos ciudades: Maastricht y Breda. La importancia simbólica y estratégica que tuvo para España la toma de ambas hizo que se les dedicaran tanto narraciones de los hechos como obras teatrales. Hay que reseñar, que lo sucedido en estas dos ciudades se repitió en muchas ocasiones a lo largo de la guerra por lo que pueden considerarse paradigmáticas.

El libro Sucesos de Flandes y Francia del tiempo de Alejandro Farnesio escrito por el soldado Alonso Vázquez, en 1614, contiene un capítulo dedicado al asedio de Maastricht y su saqueo, y Obsidio Bredana del jesuita Herman Hugo, 1626, se ocupa íntegramente del cerco y capitulación de la ciudad de Breda.

Siguiendo estas narraciones, Lope de Vega y Calderón de la Barca escribieron sendas obras, El asalto de Mastrique por el príncipe de Parma y El sitio de Bredá con el objetivo de dar a conocer los sucesos de Flandes desde la perspectiva española.

\section{MAASTRICHT Y BREDA EN LA GUERRA DE LOS OCHENTA AÑOS}

Como es sabido, Carlos V recibió por herencia de su abuela paterna, María de Borgoña, el territorio de Flandes, tierras que dejó en herencia a su hijo Felipe junto con los territorios recibidos por los reyes Isabel y Fernando. 
A pesar de ser el heredero legítimo, Felipe II siempre fue visto como extranjero por los flamencos, por otra parte, el rey no supo acercarse a sus súbditos, como ejemplo, nunca aprendió su lengua ni volvió a visitar sus posesiones del norte de Europa tras su viaje de 1548, conocido como El felicísimo viaje.

Esta falta de sintonía entre el rey y sus vasallos se puso de manifiesto en 1565 , cuando Felipe publicó los documentos tridentinos con la intención de que fueran de obligado cumplimiento en todos sus territorios. A este descontento político-religioso se añadió el económico, debido a la continua subida de precios ${ }^{7}$ que originaban las interminables guerras europeas.

El detonante de la confrontación se produjo en 1566, cuando los nobles flamencos presentaron a la gobernadora Margarita de Parma, hija de Carlos V, el llamado Compromiso de Breda, que, entre otras cuestiones, pedía que la Inquisición no se instaurara en Flandes. La negativa por parte de Felipe II a firmar este acuerdo hizo que se produjera un levantamiento generalizado ${ }^{2}$ y ante esta situación, el rey envió al duque de Alba, comenzando un conflicto que duraría ochenta años.

La guerra tuvo diferentes fases, algunas de ellas de lucha encarnizada, otras en que primaron los esfuerzos diplomáticos, una tregua de 12 años con Felipe III, a la que siguió la reanudación de las hostilidades con Felipe IV que terminarían con el tratado de Münster, 1648, que reconocería la independencia de las Provincias Unidas. De esta contienda son tres los periodos que nos interesa resaltar para encuadrar las obras estudiadas.

El primero de ellos es la etapa de Alejandro Farnesio ${ }^{3}$, que fue gobernador de Flandes y general de los ejércitos de 1578 a 1592, y al que se le puede caracterizar como un gran militar y un excelente diplomático, lo que demostró logrando que las provincias católicas se unieran en la «Unión de Arras», reconociendo a Felipe II como señor de Flandes, tal como señala Hortal ${ }^{4}$. A esta liga, las provincias rebeldes respondieron con la «Unión de Utrecht»5. Establecidas las dos coaliciones, Farnesio emprendió una campaña que resultó victoriosa y que culminó con la toma de Maastricht en 1579. El cerco, asalto y el saco de esta ciudad son los hechos que narrará el soldado Vázquez y en los que se inspirará Lope de Vega.

1. Gallegos indica sobre situación financiera de los Países Bajos: «era muy delicada, ya que las obligaciones de la enorme deuda del gobierno, legada de las guerras francesas, se tragaba las rentas ordinarias de las provincias más los 800.000 florines anuales de la concesión hecha durante nueve años por los Estados Generales. De otra parte, las tropas y la oficialidad seguían sin recibir sus pagas» (Gallegos, 2014, p. 175).

2. En relación con esta rebelión, Gallegos señaló: «El 14 de agosto de 1566, [...] grupos de calvinistas incontrolados asaltaron la iglesia de Saint-Omer, y el día siguiente se multiplicaron los asaltos, [...] así como persecución y asesinato de católicos, en varias localidades. Los desmanes y abusos de los calvinistas prosiguieron durante varios días en lo que fue llamada "furia iconoclasta"» (2014, p. 190).

3. Tras la destitución del duque de Alba, fue nombrado Gobernador Requesens con instrucciones para negociar con los rebeldes menos radicales, tal como recoge Gallegos (2014, p. 206), y tras el breve periodo de don Juan de Austria, Alejandro Farnesio, hijo de Margarita de Parma, asume el poder en Flandes. 4. Hortal Muñoz, 2004, p. 94.

5. Estas dos "uniones" darían lugar a Bélgica y Países Bajos con muy pocas variaciones. 
Tras la muerte de Farnesio, Felipe II otorga la soberanía de las Países Bajos a su hija Isabel Clara Eugenia y a su marido el archiduque Alberto, hermano del emperador Rodolfo II. A este nombramiento le siguió una época sin graves enfrentamientos, pero en 1601, Nassau conquistó la ciudad de Remberch y como respuesta el archiduque decidió poner sitio a la ciudad costera de Ostende, cuyo puerto era vital para la zona católica ${ }^{6}$. El largo asedio de esta ciudad fue, probablemente, lo que llevo a Lope a componer su obra sobre Maastricht, teniendo en cuenta la fecha en que fue escrita.

Tras esta victoria de Spínola, las Provincias rebeldes ofertaron el cese de hostilidades, en gran parte debido a la ocupación de numerosas plazas, además de Ostende, y de los fuertes en las riberas del Rin, tal como recoge García García’, y en 1609 se firma un tratado de paz por doce años ${ }^{8}$. Este acuerdo, debe contextualizarse como indica García García en «una Europa que se ve transformada por una decidida voluntad de negociación que trata de poner freno a las dinámicas heredadas de guerras civiles, enfrentamientos dinásticos y beligerancia internacional»9.

El tratado expiró en $1621^{10}$, debido a que ninguna de las partes desea renovarlo. En lo que respecta a España, Parker indica que «la tregua de los doce años no se prolongó fundamentalmente por el miedo de España a perder su dominio en las Indias» ${ }^{11}$, y en los que se refiere a las Provincias Unidas el descontento con las consecuencias de la tregua era aún mayor, pues como reseña Manzano Baena: «Allí, la paz había tenido como fruto el peor cáncer que podía atacar a cualquier república: la discordia» ${ }^{12}$.

En 1624, Spínola, general de los ejércitos en Flandes, marcha hacia Breda. En esos momentos, los tercios necesitan de una importante victoria para elevar su moral, tal como reflejó Casa ${ }^{13}$, y la toma de Breda lo fue por su significación tanto a nivel estratégico como simbólico ${ }^{14}$. El sitio duraría once meses y terminaría con

6. La toma de Ostende se planteó como una acción rápida, sin embargo, el sitio se alargó durante tres años, por la falta de hombres y de recursos monetarios. El asedio fue el más largo de todos los producidos en la guerra de los Ochenta Años y en todas las demás guerras de la época en Europa, con un elevadísimo número de muertos.

7. García García, 2012, p. 33

8. Según Retortillo Atienza: «Para algunos historiadores la firma de la Tregua de los Doce Años supuso el principio del declinar de la política de Felipe III pues en Europa se entendió como una capitulación» (2016, p. 551), lo que debilitó su posición en los Países Bajos y de cara a otros reinos europeos.

9. García García, 2012, p. 20.

10. 1621 fue el año en que comenzó a reinar Felipe IV y tras la muerte de Alberto sin descendencia los Países Bajos vuelven a la corona española.

11. Parker, 2019, p. 166.

12. Manzano Baena, 2012, p. 488.

13. Casa, 2005

14. Breda era la cuna de los Nassau, y a lo largo de la guerra se tomaron en ella importantes decisiones políticas. En el transcurso del conflicto cambió de manos en más de una ocasión, la última de forma vergonzosa para el ejército de la corona, por lo que Farnesio hizo decapitar a los capitanes italianos de la guarnición. Este hecho es recogido tanto por Hugo como por Calderón. 
la rendición de la ciudad por parte de Justino de Nassau. El cerco de la ciudad y su rendición fue la historia que contaron Hugo y Calderón.

\section{LOS AUTORES Y SUS OBRAS}

Alonso Vázquez fue un soldado nacido en Ocaña a mediados del siglo XVI que acompañó a Alejandro Farnesio durante todas sus campañas en Flandes y Francia. Su obra, Sucesos de Flandes y Francia del tiempo de Alejandro Farnesio, dedicada a Felipe IV ${ }^{15}$, que recoge sus recuerdos, es la obra más extensa escrita sobre la guerra de los Ochenta Años ${ }^{16}$. A su regreso a España, siendo responsable de las milicias en Jaén, escribió su obra, entre 1610 y $1614^{17}$. Vosters cree que tanto las comedias El asalto de Mastrique como El Sitio de Bredá debieron de servirse del manuscrito de Alonso Vázquez, afirmando que «el triple ascendiente de Vázquez, Lope y Hugo determinó, de primera instancia, la expresión dramática de El Sitio de Bredá» ${ }^{8}$.

Por su parte, Herman Hugo ${ }^{19}$, nacido en Bruselas en 1588, fue un destacado escritor jesuita que estudió filosofía y teología en la ciudad de Lovaina. Su obra más conocida es Pia Desideria ${ }^{20}$, escrita en 1624, un libro devocional con un gran número de emblemas religiosos de gran calidad. Hugo fue capellán militar de las tropas españolas en Flandes desde 1622 y confesor de Spínola, y tras la toma de Breda, de la que fue testigo, publicó en $1626^{21}$ Obsidio Bredana, dedicada a la infantagobernadora, obra en la que narró el cerco, así como las condiciones de rendición de la ciudad de Breda. De la importancia de esta obra da muestra su portada que fue diseñada por Rembrandt22.

El que Vázquez fuera soldado y Hugo sacerdote y hombre de gran cultura, influye en la forma de narrar los acontecimientos y en la propia estructura de las obras, pues el soldado se encuentra más cercano a la tropa, detalla la vida del cuartel, destacando la valentía de soldados, sus trabajos y penurias, sin que eso le impida narrar con objetividad la brutalidad del saco. Por su parte, Hugo constata tanto los hechos significativos de la campaña como el contexto de relaciones internacionales del conflicto de España con las Provincias Unidas, incluye las condiciones de la

15. Si bien pudiera ser una errata, y estar dedicada a Felipe III, habida cuenta la fecha en que Vázquez terminó de escribir su obra.

16. «Alonso Vázquez legó el más extenso testimonio histórico de que se dispone sobre las guerras de los Países Bajos» (http://dbe.rah.es/biografias/49822/alonso-vazquez). La biografía de Vázquez se encuentra sin paginar.

17. Como se recoge en la web de la Academia de la Historia: «no cabe duda de que el autor conservaba notas personales y "papeles de personas fidedignas", fruto de la correspondencia que sostuvo con sus antiguos camaradas de armas en sus empleos y destinos posteriores».

18. Vosters, 1974, p. 12.

19. Los datos de la biografía de Hugo se han obtenido del Diccionario Histórico de la Compañía de Jesús, t. II, p. 1965.

20. Su título completo es Pia Desideria. Emblematis elegiis et affectivus SS. Patrum Ilustrata.

21. En 1627 se tradujo al español por Emanuel Sueyro, tal como el mismo firma en la introducción de la edición española; esta es la edición que se ha utilizado.

22. García Hernán, 2006, p. 124. 
paz, así como varias cartas de la infanta, el rey, el papa y Spínola. De la diferente condición de ambos escritores y del estilo de sus narraciones, se puede deducir que las obras iban dirigidas a diferentes tipos de lectores, más cultos y de mayor nivel social la obra de Hugo, y más cercanos al pueblo y antiguos soldados de los tercios la de Vázquez.

La obra de Lope El asalto de Mastrique por el príncipe de Parma es una comedia histórica escrita por Lope posiblemente después del año 1600, coincidiendo, con el largo y duro asedio del sitio de Ostende, tal como hemos señalado, y así, por ejemplo, Checa indica:

Es probable que se escribiera después de 1600 coincidiendo con el prolongado sitio de Ostende por el archiduque Alberto de Austria, cuya duración se extendió de 1601 a 1604. En caso de existir, la coincidencia temporal ofrecería al público de los corrales una lección cercana sobre la capacidad de los soldados de la monarquía hispánica para superar las penalidades ${ }^{23}$.

La comedia lopesca se desarrolla en dos tramas paralelas, la primera de ellas es de ambiente marcadamente militar y según recogen Checa ${ }^{24}$ y Hendriks ${ }^{25}$ se basa en el texto de Vázquez, si bien ello conlleva el problema de las fechas de una y otra obra ${ }^{26}$. En El asalto se dramatizan las actividades del ejército: obras, penurias, asaltos y el saco posterior. Lope resalta el carisma de Farnesio, así como su empeño en la conquista de la ciudad a pesar de la falta de suministros y de su grave enfermedad, junto con la valentía y generosidad de la tropa española frente a los tercios de otras nacionalidades.

La trama secundaria es propia de una comedia de capa y espada con tintes picarescos, donde el soldado Alonso, la soldadera Marcela, la flamenca Aynora, el tudesco Bisanzón y la figura histórica de don Lope de Figueroa viven un enredo amoroso.

Respecto a El sitio de Bredá, la fecha de su representación puede situarse en el entorno de 1628, como recogen, entre otros, Coenen ${ }^{27}$ y Udaondo ${ }^{28}$ basándose

\footnotetext{
23. Checa, 2010, p. 584.

24. Checa, 2010, p. 581.

25. Hendriks 1980 , p. 376.

26. Vázquez señala «hasta el año 1610 [...] que me dio ánimo» (Los sucesos de Flandes y Francia del tiempo de Alejandro Farnese, pp. 9-10) y en la primera página del libro, en la dedicatoria lo fecha el 1 de mayo de 1614. Por otra parte, además de Checa, Hendriks fecha la obra de Lope entre 1600 y 1606 (1980, p. 376), y Di Pastena en su edición de la comedia de 2002 la data entre 1603 y 1604, es decir coincidiendo con el sitio de Ostende. Por otra parte, sabemos que la obra se editó en 1614, el mismo año que la obra de Vázquez. A la vista de estas fechas surge la duda de que Lope pudiera consultar la obra del soldado, salvo que el militar tuviera unos apuntes previos que el dramaturgo pudiera consultar. No obstante, no es objetivo de este artículo la investigación de la veracidad de estas fechas y el conocimiento o no de Lope de la obra de Vázquez.

27. Coenen, 2008.

28. Udaondo, 2012
} 
en el hecho de que Obsidio Bredana ${ }^{29}$ se tradujo al castellano en 1627, y el general Espínola estuvo en España en 1628, por lo que la obra pudo ser compuesta para representarse en su presencia.

El sitio de Bredá dramatiza el cerco de la ciudad de Breda y su toma por el ejército de Spínola. Esta victoria fue muy celebrada en la corte, pues suponía la conquista de una ciudad de gran relevancia tanto en el aspecto político como estratégico. A través de este hecho histórico, Calderón no solo va a elogiar el triunfo de las tropas del rey sobre los rebeldes flamencos, sino que va a reflexionar sobre la guerra en tres aspectos: cómo deben ser la guerra y la paz justas, las características que debería tener un soldado y el sufrimiento que acarrea la guerra en la población civil, de ahí que su trama secundaria es más tragedia que comedia, pues en ella tres personajes civiles flamencos: Flora, una dama viuda, su padre y su hijo sufren las penurias que ocasiona el cerco de Breda en sus habitantes.

Las dos comedias, al igual que las narraciones históricas, tienen muchos aspectos en común, el primero es que desarrollan un hecho histórico de especial relevancia, destacando la personalidad y la pericia de los generales, así como la valentía y pundonor de los españoles; igualmente en ambas obras se reafirma los derechos del rey Habsburgo a ser señor de Flandes y se apoya la guerra en defensa del catolicismo, más en Lope que en Calderón.

No obstante, las comedias difieren en dos facetas básicas. Por una parte, la realidad histórica de lo sucedido tras la toma de la ciudad; por otra, la trama secundaria que desarrollan ambos dramaturgos. La una como se ha dicho es propia de una comedia de capa y espada, puede suponerse que tanto para aliviar la brutalidad del saqueo como para divertir al público de los corrales. Por su parte, Calderón escribe esta segunda trama desde la perspectiva de la población civil sitiada. El planteamiento de esta línea secundaria conlleva a que en un caso el autor, Lope, se burle de los flamencos y en el otro, Calderón, se les trate con gran consideración, haciendo de Flora la heroína que se rebela contra la resistencia de Breda:

$$
\begin{aligned}
& \text { ¿Es Bredá acaso Numancia? } \\
& \text { ¿Pretende tan necia gloria? (Jornada III, vV. 145-146) }
\end{aligned}
$$

Al igual que ocurre con las obras de Vázquez y Hugo, las de Lope y Calderón iban también dirigidas a públicos diferentes, la de Lope fue escrita para los corrales, y la de Calderón para la corte, lo cual no equivale a que no se representara también en los corrales.

29. Para otros analistas, como Alcalá-Zamora (2001), la obra fue escrita y representada en palacio poco tiempo después de la rendición de Breda, para ello se basa en el supuesto de la presencia de Calderón en los Países Bajos como soldado; pero este hecho no está demostrado. 


\section{LA INGENIERÍA Y LOS TERCIOS ESPAÑOLES}

Las obras que se analizan tocan muy diversos aspectos de los hechos que acaecieron en los asedios de Maastricht y Breda, por lo que no es factible analizarlos todos en este artículo. Por este motivo, serán los que se refieren a las obras de ingeniería y a la actuación de los tercios españoles y de sus generales los que se desarrollaran por la importancia que tuvieron en la toma de estas dos ciudades y en las obras que se examinan.

\section{LA INGENIERÍA Y LA TOMA DE LAS CIUDADES}

A partir del siglo XVI, debido al desarrollo de la potencia artillera, comenzaron a edificarse fortalezas poligonales con baluartes ${ }^{30}$, en donde se situaba la artillería defensiva, se utilizaron nuevos materiales en su construcción y se cavaron grandes fosos para impedir que el ejército enemigo se acercara, por lo que para rendir estas fortalezas, que circunvalaban a grandes ciudades, solo cabía cercarlas y rendirlas por hambre, como señala Mayoral Guiu:

La rendición de estas plazas abaluartadas, a las que se denominaban como de traza italiana, requería un bloqueo total de los mismos puesto que solo se podían rendir por hambre, prolongar los asedios, acometer obras de fortificación alrededor del perímetro y un círculo de contención llamado contravalación para rechazar contrataques de los sitiados ${ }^{31}$.

En este sentido, Calderón hace decir al capitán Barlanzón:

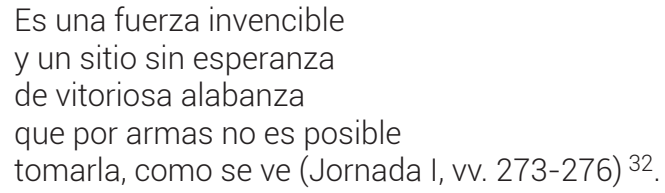

Para añadir después que solo por hambre se podía conquistar. Este hecho es de gran importancia en una guerra que se basó en la toma de ciudades, no en batallas en campo abierto.

Por otra parte, la orografía de los Países Bajos es singular, no solo por sus accidentes naturales: numerosos ríos, zonas pantanosas y su intricada costa, sino por los trabajos de sus habitantes que han construido diques desde tiempo inmemorial para ganar tierra al mar, así como para controlar las crecidas de los ríos y las mareas.

30. Obra de fortificación que sobresale en el encuentro de dos lienzos de muralla y se compone de dos caras que forman ángulo saliente, dos flancos que las unen al muro y una entrada.

32. Citamos por la edición de Rodríguez Cuadros, 2001 
La evolución de las fortificaciones y la orografía originaron la necesidad de importantes y novedosas obras de ingeniería por parte de los ejércitos españoles para conseguir cercar las ciudades que se querían conquistar, por ello los tercios irán acompañados de ingenieros, estos inicialmente serán italianos, de hecho, a las fortalezas poligonales se les conoce como de «traza italiana», de ahí que Lope llame a uno de los ingenieros Gabrio que es un nombre italiano. El oficio se aprendía, como indica Mayoral Guiu: «bien como discípulos, bien en las Academias de Matemáticas y Fortificación que aparecieron a partir del último tercio del siglo XVI»33, hay que destacar que el título de ingeniero era entregado por el rey.

El sellado total de la ciudad adquirió, por tanto, un valor fundamental y tal como reseña Parker: «las obras que construían los sitiadores mejoraron científicamente hasta el punto de que también ellas podían resistir cualquier ataque» ${ }^{34}$. De hecho, Maastricht fue una de las últimas ciudades que se tomó al asalto, si bien no se hubiera conseguido sin las obras de ingeniería.

Por tanto, la potencialidad del ejército de la corona no solo se basaba en los tercios sino también en sus construcciones de confinamiento. Un ejemplo lo tenemos con las obras de ingeniería realizadas en Ostende que recogen tanto Carnera ${ }^{35}$ como Lasso de la Vega:

y así comenzó con eficaces y exquisitas trazas a poner por obra este intento inquiriendo y consultando a ingenieros y hombres insignes fabricando diques y puentes sobre el agua y macizando profundos lugares de ella sobre qué hacer fuertes, tomar puertos, plantar trincheras y artillería, combatir la fuerza y quitarle de todo punto la continuación de los socorros ${ }^{36}$.

Las obras realizadas en Maastricht y Breda fueron, igualmente, importantes y novedosas por parte de ambos bandos, de ahí que sean referidas con detalle tanto en los relatos como en las comedias, en las que aparecerán los personajes de los ingenieros.

Vázquez, en lo que respecta al cerco de Maastricht, cuenta que el príncipe de Parma mandó hacer una rampa para subir la artillería de manera que esta estuviera a un nivel superior de las murallas y así poder bombardear directamente el interior de la ciudad: «A los 15 de junio deste año se vio una cosa jamás usada en una guerra [...] un camino a mano, desde la desembocadura de las trincheras hasta encima de la muralla para subir la artillería»37; y Lope, siguiendo a Vázquez, en la jornada II plantea una escena en que el príncipe de Parma ${ }^{38}$ Ilama al ingeniero Gabrio y le dice:

33. Mayoral Guiu, 2019, p. 171

34. Parker, 2019, p. 54.

35. Antonio Carnera, Historia de las guerras civiles que ha habido en los estados de Flandes.

36. Lasso de la Vega, El sitio y presa de Ostende y plazas de Frisa, p. 112.

37. Vázquez, Los sucesos de Flandes y Francia, p. 211

38. Alejandro Farnesio fue quien perfeccionó la técnica de las contramurallas y demás elementos constructivos que permitían aislar la ciudad, tal como recoge Giménez Martín (1999). Esta técnica llegó a su máxima expresión en el cerco de Amberes, con la construcción del imponente puente Farnesio sobre el río Escalda, de más de 800 metros de largo. 


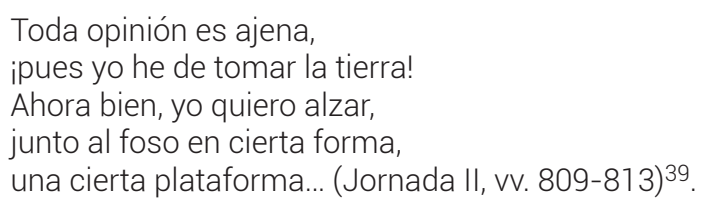

Si la obra de Lope se representó durante el asedio de Ostende, no es de extrañar que el autor diera relevancia a la ingeniería militar que tan buen resultado dio en Maastricht para dar confianza a sus espectadores sobre la victoria de las tropas de la corona.

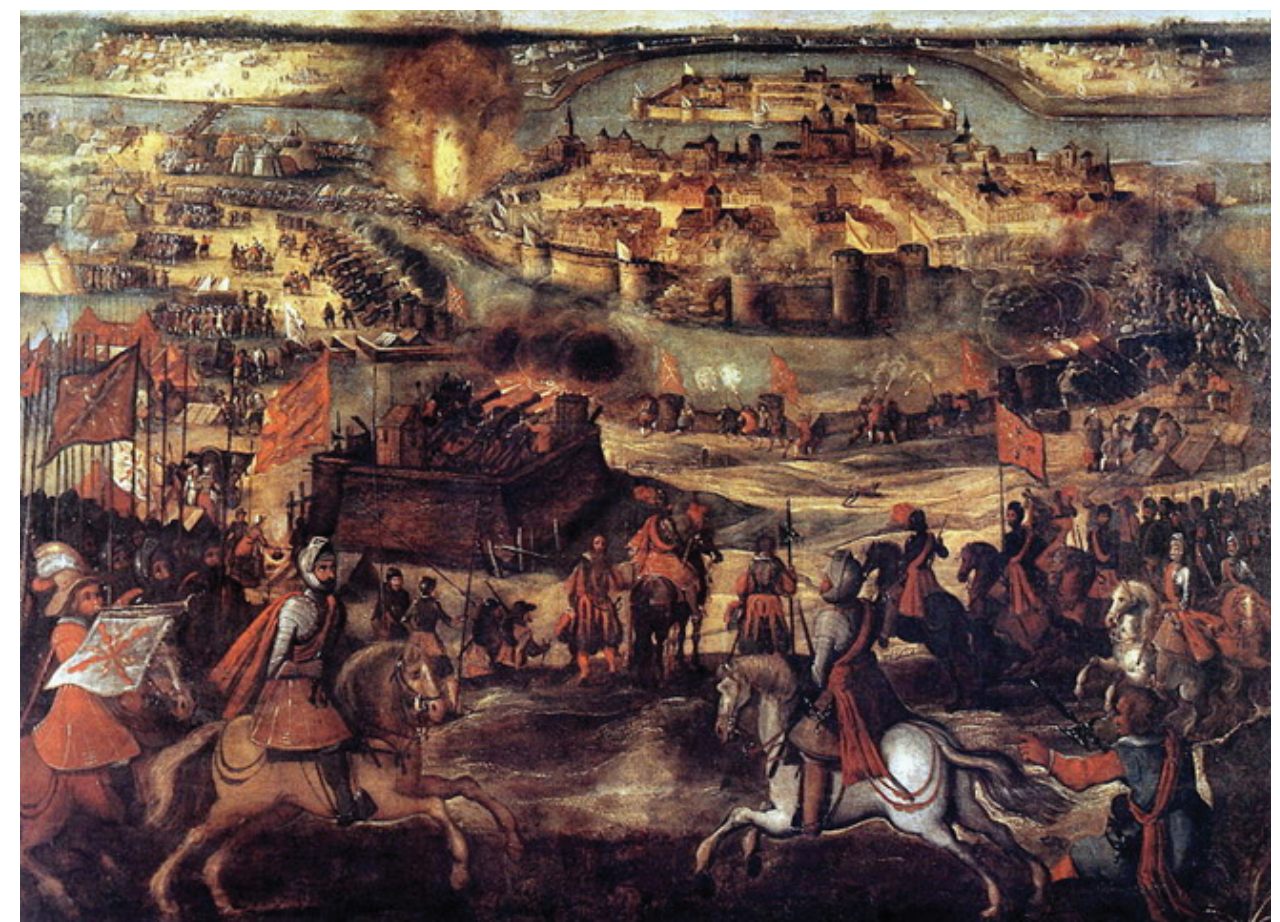

Fig. 1. El asalto de Maastricht, pintura anónima, Palacio Real de Aranjuez, España

En Obsidio, Hugo señala en su introducción: «Fueron maravillosas y nunca oídas las fortificaciones en el circuito de dos trincheras de fuera a dentro» ${ }^{40}$. El cerco de Breda fue difícil debido a la orografía de la ciudad rodeada por dos ríos, por ello, el general mandará construir fortines, diques, empalizadas, etc., para que nadie pueda entrar o salir de la ciudad. Hugo a lo largo de toda su narración describe con gran detalle las medidas que Spínola va adoptando, a modo de ejemplo: «El marqués habiendo visto los puertos que el enemigo había ganado, mando fortificar el dique con cuatro empalizadas grandes, y que desde el fuerte se llenase una trinchera hasta

39. Todos los versos de El asalto de Mastrique están tomados de la edición de Eva Soler, 2002. 40. Hugo, Obsidio Bredana, p. 10 
la orilla del río» ${ }^{41}$. Dada la envergadura de la infraestructura militar, la obra contiene un gran número de esquemas de gran calidad de las fortificaciones, los diques o las empalizadas para impedir el acceso de barcas.

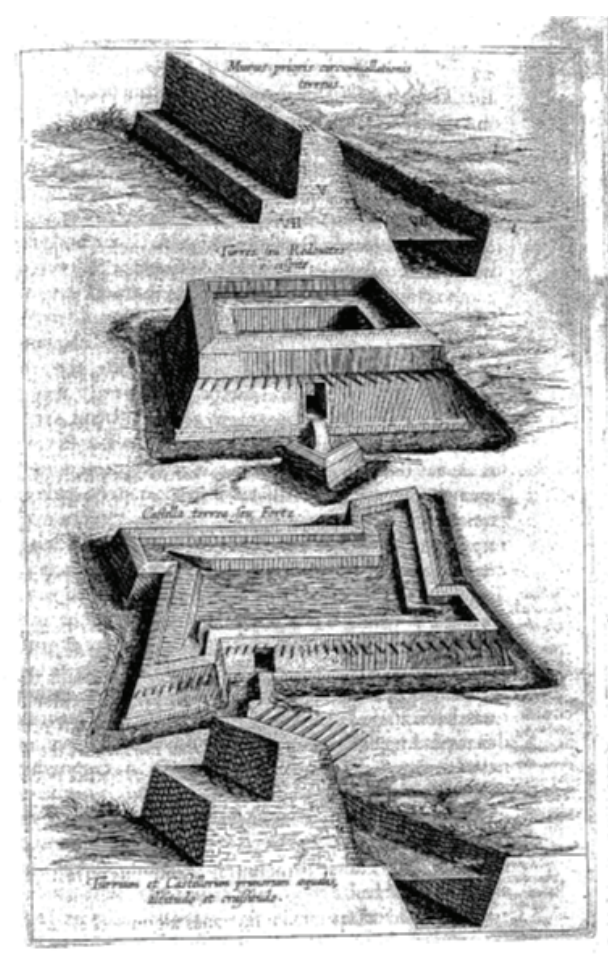

Fig.2. Esquemas de torres y contrafortalezas. Obsidio Bredana

Calderón, por boca de Espínola, dedica 196 versos a describir la contrafortaleza de Breda comparándola con Troya:

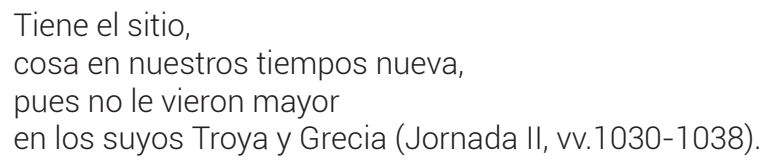

Debe reseñarse que los flamencos construyeron, igualmente, importantes estructuras, y así Vázquez ${ }^{42}$ refiriéndose al ingeniero flamenco Tapino, que diseñaría una segunda muralla interior en forma de media luna, dice de él: «dejando aparte ser enemigo de nuestra fe, no puedo excusarme que fue digno de eterna alabanza y memoria». 
Hugo, por su parte, detalla las acciones de Mauricio de Nassau y las de su hijo Enrique para levantar el cerco, para ello demolieron y construyeron diques con el objetivo de socorrer a Breda por barca; y Calderón, a través del capitán Vicente Pimentel le cuenta a Spínola los trabajos de los flamencos para inundar los cuarteles:

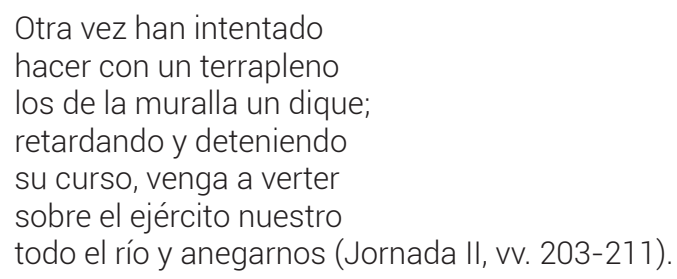

Las obras de ingeniería realizadas definen la estrategia diferente de los dos generales para tomar las ciudades: al asalto y por hambre, respectivamente.

En Maastricht se construyó una muralla exterior que contaba con 16 fortines, lo que impedía el auxilio a la ciudad, tal como pudo comprobar Guillermo de Orange que acudió con un ejército de 20.000 hombres, tal como recoge Giménez Martín ${ }^{43}$. A pesar del cerco, la ciudad no se rindió, lo que llevó a Farnesio a intentar un asalto que ocasionó un gran número de bajas en las tropas españolas, debido a la solidez de la fortaleza abaluartada. Ante este fracaso, el príncipe mandó construir una rampa a un nivel más alto que el de las murallas para situar allí la artillería y de esta forma bombardear directamente a la población, lo que facilitó un segundo y definitivo asalto. El soldado Alonso García Ramón, personaje histórico y uno de los protagonistas de la obra de Lope, fue el primero en lanzarse desde un torreón a la ciudad 44 .

En la obra de Lope es Farnesio quien dirige el asalto, aunque en realidad fueron sus capitanes, pues él estaba enfermo, y será el soldado Alonso quien, tras su hazaña, le pida a su general que sean los tercios españoles los primeros en entrar al saco, a lo que el príncipe de Parma le responde:

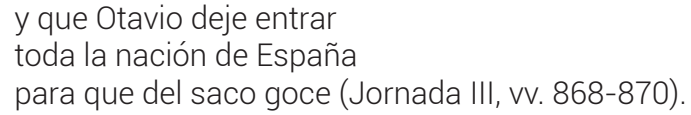

Ciertamente, los tercios españoles fueron los que comenzaron el saqueo, ya que como ariete entraron los primeros y comenzaron un saco, que, según narra Vázquez, fue brutal:

Y con la memoria de los trabajos que habían pasado en el largo y prolijo sitio con la muerte de tantos amigos, se les encendió el furor, y mezclado con alguna crueldad no perdonaban ni a niños ni a mujeres [...]. Fue un día de juicio 
[...] y muerta toda la gente rebelde, comenzaron todos los soldados a saquear la villa rigurosamente ${ }^{45}$.

Lope describirá esta violencia a través del capitán Castro:

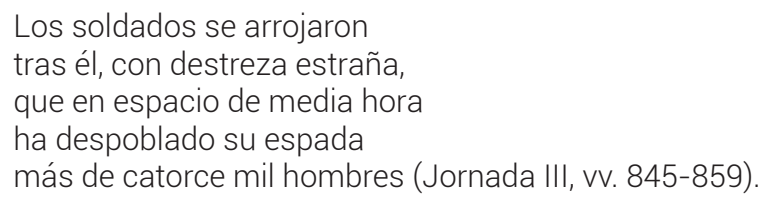

La toma de Breda fue en todo contraria a la de Maastricht. El propósito fue desde el inicio del cerco que la ciudad se rindiera por hambre y para ello selló la ciudad.

Tras el último intento fracasado de Enrique de Nassau por socorrer a la ciudad, Spínola, conocedor de la situación precaria de Breda, solo le quedaban alimentos para unos pocos días, escribió una carta a Justino ofreciéndole la paz, y el defensor de Breda aceptó. Justino fue un duro negociador, puesto que exigió que se respetara a la ciudad y a sus moradores para rendirse, Hugo recogió las condiciones en su obra:

Prométese y concédele a los burgueses y moradores de Breda, de cualquier calidad que sean, el perdón de todas las cosas que hubieren cometido, antes, o despues que se ganó la Villa en el año de 1590. No se tomará información contra ninguno, ni aun con pretexto del crimen, o de otro cualquier delito ${ }^{46}$.

Calderón, a su vez, reconoce la disposición a negociar de Spínola y las exigencias de Nassau y, siguiendo a Hugo, hace decir a Justino:

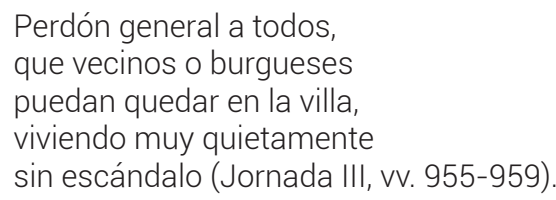

La salida de los ciudadanos y soldados de Breda se hace con toda dignidad, tanto por parte de los flamencos como por la actitud de los vencedores:

venía en medio la infantería, y entre ella Justino a caballo [...]. Llevaban las banderas tendidas [...]. El marqués [...] saludando cortésmente a cada uno de los capitanes que pasaban, y en particular al gobernador Nassau, venerable por sus canas [...]. Inclinaron (los flamencos) modestamente las banderas. No se oyó ninguna voz afrentosa de parte a parte ${ }^{47}$. 
Calderón termina su drama con la entrega de llaves por parte de Nassau a Spínola, una escena que todos tenemos en la retina, ya que Velázquez se basó en ella para su obra maestra Las lanzas o La rendición de Breda:

Aquestas las llaves son

de la fuerza, y libremente

hago protesta en tus manos (Jornada III, vv. 998-1000).

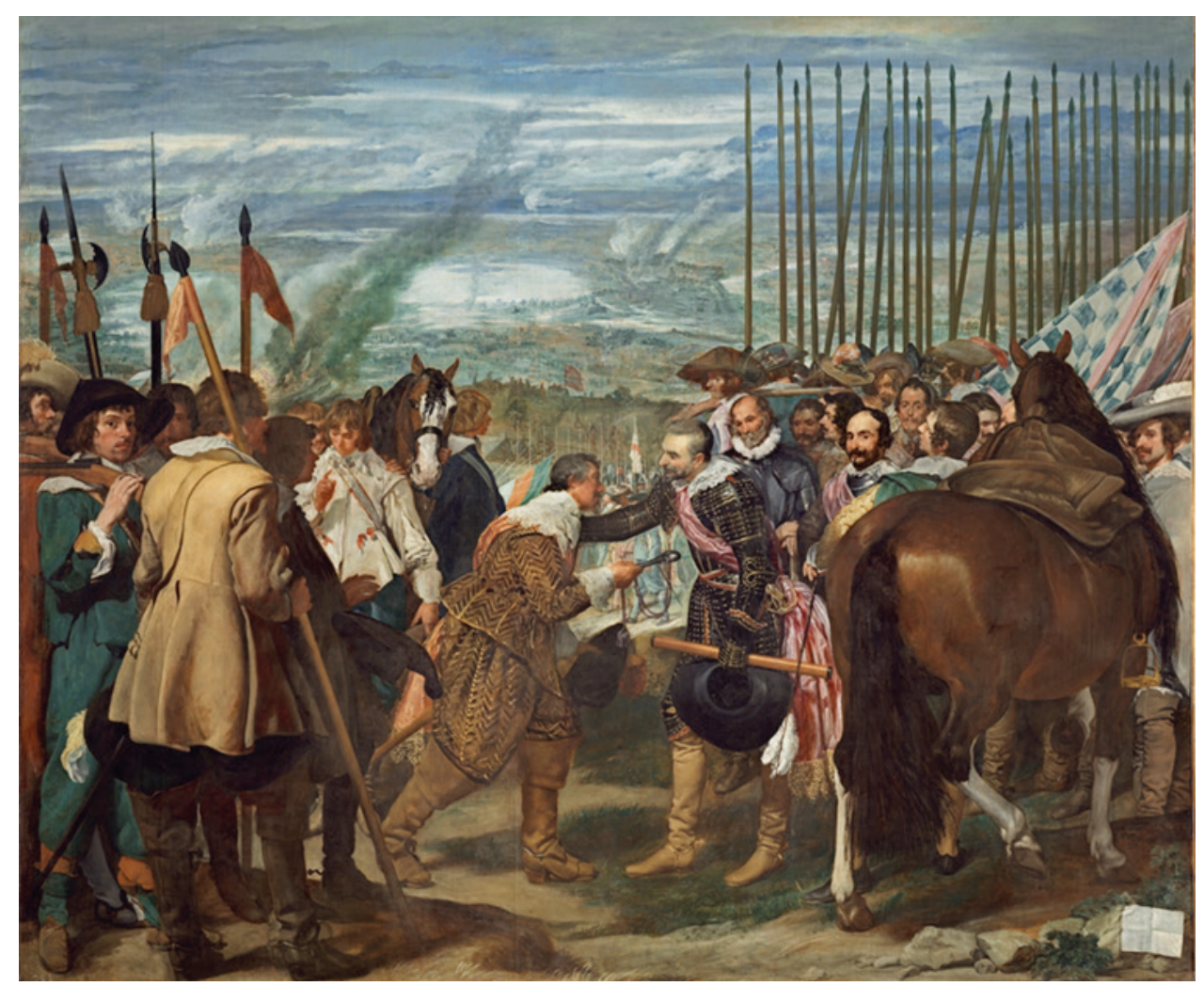

Fig. 3. Diego Velázquez, Las lanzas o La rendición de Breda, Museo del Prado, Madrid

\section{LOS TERCIOS ESPAÑOLES Y SUS GENERALES EN LA CONQUISTA DE MAASTRICHT Y BREDA}

Tanto en las narraciones como en las obras dramáticas, dos son los protagonistas esenciales, el ejército como personaje genérico o a través de soldados destacados, como Alonso, y sus generales, Farnesio y Spínola.

La fuerza base del ejército español, desde Carlos $V$, fue la infantería formada por voluntarios pagados armados de picas y armas de fuego. Su formación y arrojo hicieron de ella un cuerpo formidable y prácticamente imbatible durante el 
siglo XVI y parte del XVII. Esta infantería estaba dividida en tercios, de ahí su nombre, o banderas tanto españolas como por contingentes que se conocían como de «naciones», alemanes, italianos, albaneses, valones, irlandeses, loreneses, borgoñones e ingleses.

Los tercios españoles eran los mejor formados, tal como señala Quatrefages: «La particularidad y la superioridad de la técnica española para disponer de tropas aptas y adiestradas consistían en utilizar la infantería estacionada en Italia, reemplazándola por otra recientemente reclutada en España» ${ }^{48}$. De esta forma, los españoles que iban al combate a Flandes eran soldados curtidos en Italia, constituyendo lo que Albi de la Cuesta denomina «ballenas de corsé» y explica esta denominación señalando que son

fuerzas selectas que constituyen una minoría del ejército, pero que dan solidez al conjunto [...]. En la larga guerra en los Países Bajos, raramente hubo más de tres o cuatro tercios españoles, lo que suponía unos siete mil hombres, entre el quince y el veinte por ciento del ejército ${ }^{49}$.

Los cuatro autores que se analizan destacan este hecho, y en sus comentarios y versos siempre resaltan la disciplina, valentía y sentido del honor de estos tercios frente al resto de naciones.

En este sentido, Vázquez comenta: «pues ellos (los españoles) eran sus verdaderas fuerzas que tenía para oponerse a cualquier ocasión que se ofreciese, demás de ser freno a las demás naciones y ejemplo a todo su ejército por estar bien disciplinados y en obediencia» 50 .

Igualmente, Hugo expone la diferencia entre españoles y los tercios extranjeros: «los soldados extranjeros más acostumbrados a correr licenciosamente la campiña, que a nuestra disciplina [...] comenzaron a robar las casas, asolar las aldeas, acometer como enemigos a nuestros convoyes» ${ }^{51}$.

Los dramaturgos dan un mayor énfasis a las virtudes de los españoles, pues los dibujan como héroes fieles a su rey y a su patria. Lope, a través del capitán Castro dice de ellos:

¡Oh espanto de otras naciones, gloria a la patria que os dio este fuerte corazón! (Jornada II, vv. 901-903).

48. Quatrefages, 2015, cap. 3.

49. Albi de la Cuesta, 2017, p. 16.

50. Vázquez, Los sucesos de Flandes y Francia, p. 219

51. Hugo, Obsidio Bredana, p. 94. 
Por su parte Calderón ${ }^{52}$, a través del lugarteniente de Spínola dice de los españoles:

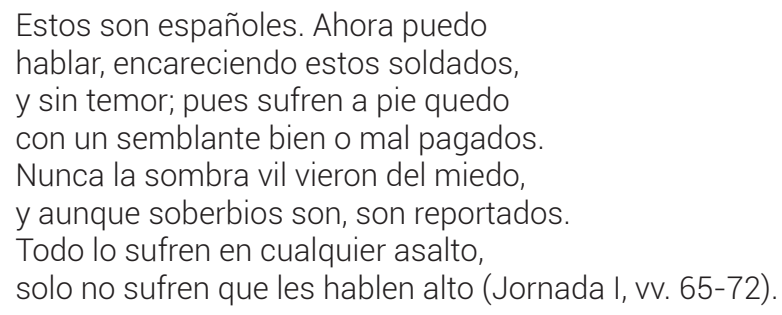

Es cierto que a pesar de motines y deserciones ${ }^{53}$ y que luchaban por dinero, los españoles eran fieles a su rey y a su bandera, lo que es resaltado muy especialmente por los dramaturgos. Así, cuando el capitán Castro, en El asalto, va a pedir dinero a los tercios españoles, estos a través del capitán Perea contestan:

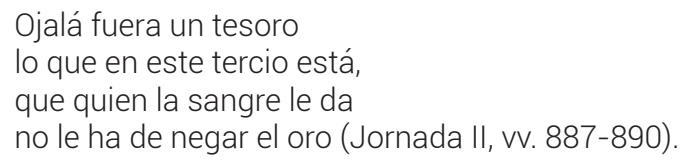

Y todos, incluido el soldado Alonso que al principio de la obra se encontraba a punto de desertar, le dan sus joyas y su dinero. Una vez que toda la bandera ha dado lo que posee para que el príncipe de Parma pueda continuar con el asedio, Alonso dice:

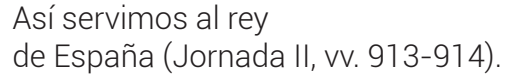

En El sitio de Bredá, Spínola recorre los diferentes cuarteles para preguntar la opinión de los tercios sobre que se pacte la rendición de la ciudad y, por tanto, no haya saqueo. Los tercios de las diferentes naciones exigen el saco, mientras que el cuartel español aceptará la propuesta de su general, pues lo importante es que Breda vuelva a ser posesión de Felipe IV:

$$
\begin{aligned}
& \text { nuestra gloria conseguida, } \\
& \text { dando la hacienda y la vida } \\
& \text { tan dignamente empleada, } \\
& \text { al Rey, pues mayor hazaña }
\end{aligned}
$$

52. El objetivo del dramaturgo, presente a lo largo de toda la obra, es ensalzar la hidalguía de las tropas españolas; en este sentido Coenen afirmó: «Cuando se elogia en esta comedia la valentía de los españoles, no es que Calderón quiera decir que los españoles fueron los más valientes en Flandes; quiere decir que deben aspirar a serlo siempre» (2008, p. 37).

53. Albi de la Cuesta en relación con los motines escribe: «en los españoles el sentido de lealtad a su soberano, con exclusión de cualquier otro, constituye algo esencial. No sirven al mejor postor, sino a una bandera específica, y solo a ella» (2017, p. 1). 
es que no manche en tal gloria con la sangre la vitoria, y sea Bredá de España (Jornada III, vv. 599-605).

Hugo no hace ninguna mención a esta visita por los cuarteles de Spínola, por lo que esta escena la podemos considerar como una licencia de Calderón para imprimir más fuerza dramática a su obra y elogiar a los soldados españoles. Greer indicó sobre esta escena: «Calderón, who concludes this play with the disclaimer that he could do no more, being subject to so many commands, dramatizes Spanish soldiery en masse as valiant and generous» ${ }^{54}$.

A pesar de ser el ejército más potente del mundo, los tercios sufrieron una escasez endémica durante los años que duró la contienda, que no podía ser obviada ni por narradores ni por dramaturgos, y que se solventaba con la llegada de los galeones de América o con los sacos ${ }^{55}$, si la plata que arribaba a España no era suficiente.

Los problemas de abastecimiento se referían no solo a alimentación y pagas, también a material de guerra, como recoge Vázquez: «No fue posible cuando el sitio de Mastriq que se librase la cuerda necesaria, pólvora y otras municiones a los soldados de las trincheras» ${ }^{56}$. Por su parte, Hugo explica: «y se padeció en todo carestía. No recibiendo los soldados más de media paga, y pocas veces» ${ }^{57}$.

El que no llegaran las pagas tenía una gran importancia porque el soldado de los tercios debía alimentarse, vestirse y alojarse por su cuenta, como indica Quatrefages. Por otra parte, debe indicarse que «en comparación con su sueldo, lo que le reportaba un botín era una cantidad enorme» 58 y más en algunas de las riquísimas ciudades de Flandes.

Esta situación, que debía ser bien conocida en España, es denunciada por los dramaturgos, en sus obras no solo se alaba la valentía de los tercios y sus victorias, también se pone de manifiesto sus penurias, y así tanto Lope como Calderón comienzan sus obras con el descontento de los soldados.

Lope lo hace a través del soldado Alonso, el héroe de la obra al ser el primero que entra en Maastricht:

54. Greer, 2009, p. 211.

55. Uno de los mayores problemas con el que se encontró el ejército de la corona en la guerra de los 80 años, fue la paga de los soldados. Como es sabido el estado de la hacienda española durante los reinados de los Austrias fue lamentable debido a las numerosas contiendas a las que hizo frente. Esto trajo consigo 7 bancarrotas entre los siglos XVI y XVII, por lo que la paga de los soldados fue irregular y dependía de la plata que los galeones traían de América, lo que estaba supeditado a tormentas y piratería. 56. Vázquez, Los sucesos de Flandes y Francia, p. 196.

57. Hugo, Obsidio Bredana, p. 10

58. Quatrefages, 2015, cap. 9. 
Mientras un hombre no muera,

denle a comer y beber,

¡no hay más de andar sin comer

tras una rota bandera! (Jornada I, vv. 17-20).

El dramaturgo aúna en un mismo personaje al soldado a punto de desertar con el héroe, con lo cual aprueba y justifica, ante los espectadores españoles, las protestas del soldado, tal como reconoce Hendriks:

Por eso, Lope de Vega, al elegir precisamente a este héroe del famoso asalto para dicho soliloquio, tan expresivo de la miseria de la guerra, acierta a dar más relieve al sufrimiento y la perseverancia de los soldados del ejército de Flandes, ya que hasta para un hombre de la talla de un Alonso García esta vida guerrera llega a ser insoportable ${ }^{59}$.

La falta de paga y los amotinamientos son recalcados por los autores, quizá como una forma de denunciar ante el rey y el pueblo la pobreza que soportaban los tercios españoles en Flandes, y tal vez para facilitar la recaudación de impuestos. Lope, tras la queja de los soldados, hace reconocer a Farnesio:

Tengo temor que amotinarse quieren, porque la sed y hambre los aflige,

y ha mucho tiempo que la paga esperan (Jornada I, vv. 271-273).

Calderón, asimismo, expone las razones de Spínola para emprender el sitio. El frío del invierno traerá muchas penurias, por lo que necesita iniciar un cerco para que los soldados no se amotinen con la esperanza de un saqueo:

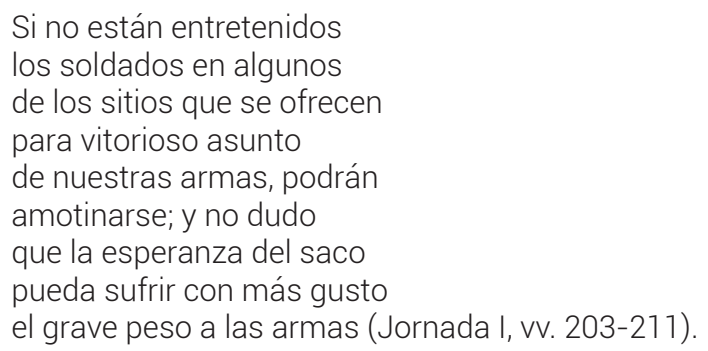

En relación con los generales, debe reseñarse que desde Carlos $\vee$ ningún rey de la Casa de Austria se puso al frente de sus ejércitos. El mando era, por tanto, una delegación que el monarca hacía en un hombre de su confianza y así lo entendían los generales. Vázquez, en este sentido, escribe con respecto al duque de Parma: «no poner la mira en otra cosa que al servicio de Dios y al Rey, nuestro señor»60; y 
Hugo señala: «y juzgando así mismo que debía más tener en cuenta la clemencia y majestad de su rey, cuyas partes hacía en su lugar, que con su propia gloria o venganza» ${ }^{61}$.

La razón por la que los ejércitos se encuentran en Flandes es porque su rey les ha enviado a luchar contra sus súbditos rebeldes y esta idea la recoge de forma contundente Lope, a través de Farnesio:

¡Pues por vida de Alejandro que has de ser del Rey, Mastrique! (Jornada III, vv. 48-50).

Igualmente, en El sitio de Bredá, Spínola declara con una frase muy calderoniana:

El alma y la vida es poco, que la hacienda de derecho natural es suya (Jornada II, vv. 109-111).

Farnesio como Spínola fueron generales carismáticos por su valor y su conocimiento del arte de la guerra, y así Vázquez dice: «El invictísimo Alejandro Farnesio, príncipe de Parma, tan parecido en el valor y obras a Magno Alejandro como en el nombre» ${ }^{62}$. Por otra parte, Farnesio está convencido de que la guerra que hace contra los flamencos es justa, puesto que combatía a súbditos rebeldes, y así lo recoge Lope:

¿Qué haré, guerra, qué haré? Seguir la guerra,

y abrase el fuego los flamencos yelos

hasta que se reduzga al Rey su tierra,

Felipe tiene aquí de sus agüelos

el patrimonio (Jornada III, vv. 653-657).

Tanto Vázquez como Lope presentan al príncipe como buen líder y cercano a sus hombres, así, por ejemplo, les ayuda en los trabajos de cavar trincheras o hacer túneles ${ }^{63}$ : «y por su mano ayudaba a atacar las minas como si fuera el menor soldado o gastador de su ejército» ${ }^{64}$. Lope refiere también este hecho y frente a la opinión de Figueroa de que cavar es para gente rústica, Farnesio responde:

No hay, don Lope,

cosa en la guerra que no sea decente

al mismo General, si hacello importa (Jornada II, vv. 529-531).

61. Hugo, Obsidio Bredana, p. 121

62. Vázquez, Los sucesos de Flandes y Francia, pp. 222-223.

63. El general cercano a sus hombres que no rehúye ningún trabajo físico es recogido por Cervantes, en La Numancia; dice Escipión: «Yo mismo tomaré el hierro pesado / y romperé la tierra fácilmente» (Jornada I, vv. 333-334).

64. Vázquez, Los sucesos de Flandes y Francia, p. 192. 

apuntó:

De esta obra y de la relación entre Alejandro Farnesio y sus soldados, Checa

El texto de Lope aprovecha la heterodoxia militar de Farnesio para proponer un modelo heroico no menos singular, donde el general encarna junto a sus oficiales y soldados tanto el sufrimiento como la familiaridad con la muerte, inspirando a todos con su ejemplo65.

Spínola se constituye, igualmente, en el protagonista de las obras de Hugo y de Calderón. Hugo le presenta como un verdadero líder, prudente, como se observa al pedir consejo a sus capitanes, y valiente: «Apenas habían pasado cuatro días, cuando yendo el marqués en un caballo blanco [...], le llevó un cañonazo el freno por debajo de la cabeza del caballo [...] dejándole en las manos la rienda» ${ }^{66}$. Calderón traslada este hecho a la escena:

Quitome el freno al caballo,

mas si no me alcanzó el golpe,

lo mismo fuera haber dado

en Toledo (Jornada III, vv. 187-194).

Además, el dramaturgo le muestra sagaz, y así para conseguir que los tercios acepten su negociación de la paz, decide:

Mas yo sabré con prudencia

obligarlos, recorriendo

los cuarteles y pidiendo

su voto y su conveniencia (Jornada III, vv. 546-549).

\section{CONCLUSIONES}

La interminable guerra de Flandes no solo supuso una sangría de hombres y recursos materiales también condicionó la vida de los españoles, muy especialmente de los castellanos. No es de extrañar, por tanto, que quienes vivieron de primera mano los sitios de las ciudades al igual que los dramaturgos escribieran sobre la guerra y sus vicisitudes, pues como apunta Díez Borque: «Se promueve también desde las tablas una política militar que lleva consigo el ensalzamiento de los valores de la guerra y del soldado, con el heroísmo como virtud suprema» ${ }^{67}$, frase que puede hacerse extensiva al género narrativo.

Los cuatro autores analizados tienen, como se ha visto, muchos puntos en común en su tratamiento de los hechos como son: la importancia dada a la ingeniería militar, la preparación de los tercios españoles frente a las otras banderas, la heroicidad de soldados y generales, la legitimidad del rey Habsburgo de guerrear contra 
sus súbditos rebeldes y la defensa de la fe católica, esto a pesar de sus diferentes estilos, perspectivas y a que se dirigían a públicos dispares, por lo que se puede suponer que presentan situaciones no muy alejadas de la realidad, desde el punto de vista de los españoles.

Toda esta exaltación guerrera muestra importantes componentes propagandísticos y también didácticos, a fin de difundir entre el pueblo las victorias de la monarquía, así como las razones para que el pueblo apoyara a su rey en la interminable guerra de Flandes, facilitando de esta forma el alistamiento, el pago de impuestos y la paz social, sin olvidar el factor cultural, pues como reseña García Hernán: «se da en la España del Siglo de Oro incluso una conciencia de que con las letras, con la cultura, también se puede vencer al enemigo» 68 , pues la guerra debía estar muy presente en todos los ámbitos española, como demuestra los diferentes públicos a los que se dirigen las obras comentadas.

Los autores dramáticos tenían, por su puesto, una mayor capacidad de divulgación de los hechos acaecidos en Flandes que las narraciones más o menos históricas; pues el teatro también era entretenimiento y en esto Lope y Calderón, soldados ellos también ${ }^{69}$, fueron maestros.

Por último, no nos podemos olvidar de que en las obras estudiadas aparece la denuncia de las privacione ${ }^{70}$ que sufrían los tercios, la tremenda dureza de las campañas en una guerra librada a cientos de kilómetros de los hogares, sin que por ello los autores olviden los sufrimientos de los civiles flamencos. Vázquez no ahorra detalles sobre la brutalidad de los tercios una vez que comienza el asalto y Calderón nos describe el padecimiento de los sitiados a través de Flora y su familia.

\section{BiBLIOGRAFÍA}

Albi de la Cuesta, Julio, De Pavía a Rocroi. Los tercios españoles, Madrid, Desperta Ferro ediciones, 2017.

Alcalá-Zamora y Queipo de Llano, José, «Homenaje a don Pedro Calderón de la Barca», Militaria. Revista de cultura militar, 15, 2001, pp. 75-78.

Calderón de la Barca, Pedro, El sitio de Bredá, ed. Evangelina Rodríguez Cuadros, Alicante, Biblioteca Virtual Miguel de Cervantes, 2001.

Casa, Frank, «Velázquez, Calderón y el sitio de Breda», en Estudios de teatro español y novohispanos. Actas del XI congreso de la Asociación Internacional del Teatro Español y Novohispano del Siglo de Oro, Buenos Aires, Facultad de Filología y Literaturas Hispánicas, 2005, pp. 293-301. 
Carnera, Antonio, Historia de las guerras civiles que ha habido en los estados de Flandes, Bruselas, Ivan de Meerbeque, 1625.

Cervantes Saavedra, Miguel de, La Numancia, ed. Francisco Sevilla Arroyo, Alicante, Biblioteca Virtual Cervantes, 2001.

Checa, Jorge, «El asalto de Mastrique: Lope de Vega y la Communitas militar», Nueva Revista de Filología Hispánica, LVIII, 2, 2010, pp. 583-617.

Coenen, Erik, «Calderón y la guerra. Del sitio de Breda al sitio de Galera», Nueva Revista de Filología Hispánica, 56.1, 2008, pp. 31-51.

Díez Borque, José María, Sociología de la Comedia española del siglo XVII, Madrid, Cátedra, 1976.

Gallegos, Federico, «La guerra de los Países Bajos hasta la Tregua de los Doce Años», Revista Aequitas. Estudios sobre historia, derecho e instituciones, V, 4, 2014, pp. 167-252.

García García, Bernardo J., «Introducción. El arte de la prudencia. La Tregua en la Europa de los Pacificadores», en El Arte de la prudencia: la Tregua de los Doce Años en la Europa de los Pacificadores, ed. Bernardo J. García García, Manuel Herrero Sánchez y Alain Hugon, Madrid, Fundación Carlos de Amberes, 2012, pp. 11-45.

García Hernán, David, La cultura de la guerra y el teatro del Siglo de Oro, Madrid, Silex, 2006.

Greer, Margaret, «Class and the Dirty Work of War in Calderón», Anuario calderoniano, 5.2, 2009, pp. 207-218.

Hendriks, Victorinus, «Algunos apuntes sobre la historicidad de El asalto de Mastrique por el príncipe de Parma de Lope de Vega», en Actas del Sexto Congreso Internacional de Hispanistas, coord. Evelyn Rugg y Alan M. Gordon, Toronto, University of Toronto, 1980, pp. 376-380.

Hugo, Herman, Obsidio Bredana, Sitio de Breda rendida a las armas del rey don Felipe IV, trad. de Emanuel Sueyro, Amberes, imprenta Plantiniana,1627.

Hortal Muñoz, José Eloy, El manejo de los asuntos de Flandes, 1585-1598, tesis doctoral, Madrid, Universidad Autónoma de Madrid (Departamento de Historia Moderna, Facultad de Filosofía y Letras), 2004, https://repositorio.uam.es/ handle/10486/2511.

Giménez Martín, Juan, Tercios de Flandes, Madrid, Falcata Ibérica, 1999.

Lasso de la Vega, Gabriel, El sitio y presa de Ostende y plazas de Frisa, dirigido a don Felipe Espinola, manuscrito con fecha de 1600, Biblioteca Nacional de España, Mss. 2346. 
Manzano Baena, Laura, «Bellum optima rerum. Elogio de la guerra en los Países Bajos tras 1609», en El Arte de la prudencia: la Tregua de los Doce Años en la Europa de los Pacificadores, ed. Bernardo J. García García, Manuel Herrero Sánchez y Alain Hugon, Madrid, Fundación Carlos de Amberes, 2012, pp. 487-505.

Mayoral Guiu, Miguel, «Los ingenieros militares al comienzo de la Edad Moderna», en Lecciones aprendidas de la historia. Los ejércitos de la monarquía hispánica (1475-1700), Madrid, Ministerio de Defensa de España, 2019, pp. 153-178, https://www.gehm.es/biblio/Ejercitos\%20Monarquia\%20Hispanica\%20-\%20 Tercios\%20-\%20Lecciones\%20Aprendidas\%20-\%20MADO.

O'Neill, Charles, y Domínguez, Joaquín María, Diccionario Histórico de la Compañía de Jesús, Universidad Pontificia, Comillas / Roma, Instituto Historicum S. J., 2001, 2 vols.

Parker, Geoffrey, El ejército de Flandes y el Camino Español. 1567-1659, Madrid, Alianza Editorial, 2019 [1. ${ }^{\text {a }}$ ed. 1985].

Quatrefages, René, Los tercios, Madrid, Ministerio de Defensa, 2015 [edición epub].

Retortillo Atienza, Asunción, Ambrosio Spínola y el ejército de Felipe III, 1569-1621, tesis doctoral, Burgos, Universidad de Burgos (Departamento de Historia, Geografía y Comunicación), 2016, https://riubu.ubu.es/handle/10259/4802.

Udaondo Alegre, Juan, «Entre la evocación épica y la crónica de guerra: El sitio de Breda de Calderón de la Barca», en Europa (historia y mito) en la comedia española. XXXIII Jornadas de Teatro Clásico, Cuenca, Universidad de Castilla-La Mancha, 2012, pp. 173-188.

Vázquez, Alonso, Los sucesos de Flandes y Francia del tiempo de Alejandro Farnese, Colección de Documentos Inéditos para la Historia de España (CODOIN), ed. Marqués de la Fuensanta del Valle, J. Sancho Rayón y Fernando de Zabálburu, vol. 72, Madrid, 1879, https://archive.org/details/coleccindedocu72madruoft.

Vega y Carpio, Félix Lope de, El asalto de Mastrique por el Príncipe de Parma, ed. Eva Soler Sasera, Alicante, Biblioteca Virtual Miguel de Cervantes, 2002, https://artelope.uv.es/.

Vega y Carpio, Félix Lope de, El asalto de Mastrique, ed. Enrico di Pastena, Lleida, Milenio, 2002.

Vosters, Simon Anselmus, La Rendición de Breda en la Literatura y el Arte de España, London, Tamesis book, 1974. 